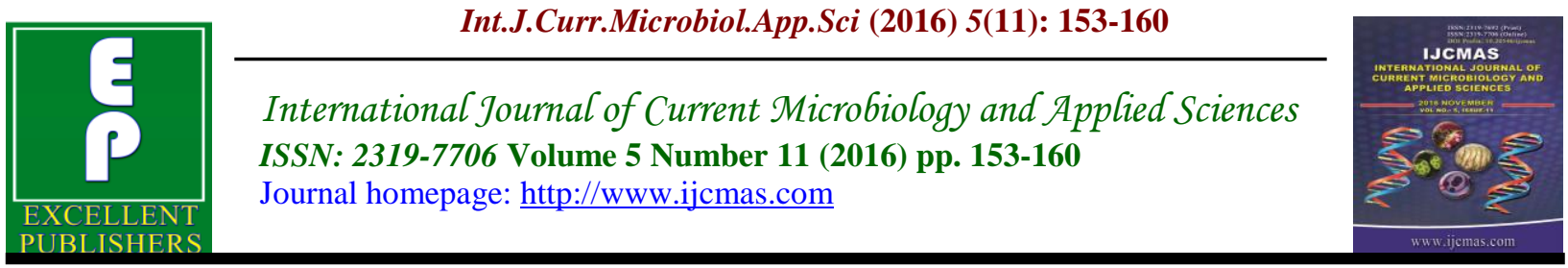

Original Research Article

http://dx.doi.org/10.20546/ijcmas.2016.511.018

\title{
Characterization of Proteus Species and Detection of Multi Drug Resistant (MDR) with Special Reference to ESBL Strains
}

\author{
Satisfaction Syntem*, Himadri Dutta and M. Kalyani \\ Department of Microbiology, Saveetha Medical College and Hospital, \\ Thandalam (Chennai), India \\ *Corresponding author
}

\begin{tabular}{|c|c|}
\hline & A B S T R A C T \\
\hline Keywords & \multirow{3}{*}{$\begin{array}{l}\text { Extended-spectrum } \beta \text {-lactamase (ESBL) continues to be a major problem in } \\
\text { healthcare settings. The current study was carried out to assist the clinicians to } \\
\text { prescribe appropriate antibiotics against gram-negative clinical isolates. Different } \\
\text { Proteus species are commonly implicated pathogens in hospital as well as } \\
\text { community acquired infections. A total of } 172 \text { Proteus species isolated from } \\
\text { exudates and urine were speciated and tested for antibiogram. ESBL screening was } \\
\text { done using } 3^{\text {rd }} \text { generation Cephalosporin's and confirmed by double disc diffusion } \\
\text { test. Among the } 172 \text { Proteus isolates, exudates }(68.02 \%) \text { showed the predominant } \\
\text { cases, with Proteus mirabilis } 117(62.20 \%) \text { as predominant isolated organism } \\
\text { followed by Proteus vulgaris } 56(32.55 \%) \text {, Providencia stuartii } 6 \text { (3.48\%) and } \\
\text { Morganella morganii } 3(1.74 \%) \text {. They were highly sensitive to Imipenem. Proteus } \\
\text { species were highly resistant to ampicillin, Ceftazidime, Aminoglycosides and } \\
\text { Quinolones showing } 70 \% \text { of multiple drug resistant (MDR) and } 3.4 \% \text { Pan drug } \\
\text { resistant (PDR) of which } 24 \% \text { of Proteus isolates were confirmed ESBL producers. }\end{array}$} \\
\hline & \\
\hline & \\
\hline
\end{tabular}

\section{Introduction}

The tribe Proteus consists of a unique group of bacteria within the family Enterobacteriaceae. Proteus can be found in animals, soil and in the intestinal tract of humans (Kamga). The tribe Proteus includes of the genus Proteus, Providencia and Morganella in which Proteus was found to be mostly involved in many of the Proteus infections and Hospital acquired infection/ nosocomial infection. The genus Proteus forms the part of the normal microbial flora of the gastrointestinal system and plays a crucial pathogenic role in human beings, both in the community as well as hospital premises. Proteus has been ranked third position in causing nosocomial infection (Nachammai; De Champs et al., 2000). Proteus mirabilis and Proteus vulgaris are widely recognised as human pathogens in which Proteus mirabilis is the most common causative agent of infection-related kidney stone and recurrent bacteriuria (Coker et al., 2000). It was also found to cause pyogenic lesions, wound infections, septicaemia and rarely meningitis (Orett, 1999). There has been a high prevalence of Proteus mirabilis, in skin abscesses, which had potential implications for selection of antimicrobial therapy and a case suppurative pericarditis 
caused by Proteus mirabilis was also identified (Mistry et al., 2010; Sawaya et al., 2009). Occurrence of various virulence factors like fimbrial antigen adhering to uroepithelium, outer membrane proteins (OMP), hemolysin production, cellular invasive property, urease and DNase enzyme production, swarming motility through quorum sensing, adds up for its colonization and progressive disease.

Wild type strains of Proteus mirabilis are usually sensitive to $\beta$-lactum group of antibiotics. However, due to indiscriminate use of $\beta$-lactum antibiotics have led to the development of resistance to this group of antibiotics due to various type of $\beta$ lactamase production. Since ESBL producing Proteus species are also found to be Multidrug resistant, it is important to know the prevalence of ESBL producing Proteus in a hospital setting, to prevent spread of nosocomial infection caused by MDR organisms.

With this background, this study was carried out to determine prevalence of various Proteus species causing infections and its antibiogram susceptibility pattern in a tertiary care hospital as well as ESBL production in them.

\section{Materials and Methods}

This laboratory based study was being done for over a period of six months from July 2015 to December 2015 in the Department of Microbiology, Saveetha Medical College and Hospital, Thandalam, Chennai, India to determine the prevalence of Multidrug resistant and ESBL producing Proteus species causing Urinary Tract Infection (UTI), Wound Infection and nosocomial infection.

A total of 172 isolates of Gram- negative bacilli obtained from clinical specimens like urine and wound/ pus swab of both hospitalized patients and out-patients were identified biochemically by the standard microbiological methods (Collee et al., 1996). Isolates from mixed culture were excluded from the study but those that show non-lactose fermenting colonies on MacConkey agar and swarming on Blood agar were isolated and identified by biochemical tests based on whether they were positive for Phenylalanine deaminase production; $\mathrm{H}_{2} \mathrm{~S}$ gas production; and urease reactions. Isolates were also tested for virulence factors including production of enzymes like Urease and DNase. The antibiogram of the isolates was determined by the Standard Kirby Bauer's disc diffusion method and Clinical Laboratory Standards Institute (CLSI) recommendations using following antibiotics discs (Hi-Media, India) Ampicillin $(10 \mu \mathrm{g}), \quad$ Amikacin $(30 \mu \mathrm{g})$, Ceftazidime $(30 \mu \mathrm{g})$, Ciprofloxacin $(5 \mu \mathrm{g})$, Cephalexin $\quad(30 \mu \mathrm{g}), \quad$ Cotrimoxazole $(1.25 / 23.73 \mu \mathrm{g}), \quad$ Cefepime $\quad(30 \mu \mathrm{g})$, Cefotaxime $(30 \mu \mathrm{g})$, Gentamicin $(10 \mu \mathrm{g})$, Ofloxacin $(5 \mu \mathrm{g})$, Imipenem $(10 \mu \mathrm{g})$. The zone diameters were interpreted as per Clinical Laboratory Standards Institute (CLSI) recommendations (2012).

ATCC Escherichia coli 25922 strain was used for quality control.

\section{ESBL screening test}

According to CLSI guidelines (2012), in disc diffusion test, those Proteus isolates with a zone inhibition of

$\leq 27 \mathrm{~mm}$ with Cefotaxime, $\leq 25 \mathrm{~mm}$ with Ceftriaxone, $\leq 22 \mathrm{~mm}$ with Ceftazidime,

$\leq 17 \mathrm{~mm}$ with Cefpodoxime, were considered potential ESBL producers and were further confirmed for ESBL production by doing double disc diffusion method (CLSI). 
ESBL confirmatory test (Double disc diffusion test)

Here overnight culture suspension of the test isolates adjusted to 0.5 McFarland's standard was inoculated by using a sterile cotton swab on a Muller Hinton Agar plate. The cefotaxime $(30 \mu \mathrm{g})$ and cefotaximeclavulanic acid $(30 / 10 \mu \mathrm{g})$ discs were placed $20 \mathrm{~mm}$ apart. Similarly ceftazidime $((30 \mu \mathrm{g})$ and ceftazidime-clavulanic acid $(30 / 10 \mu \mathrm{g})$ discs were also placed $20 \mathrm{~mm}$ apart.

After overnight incubation at $37^{\circ} \mathrm{C}$, the test organism was considered as a confirmed ESBL producer if the zone size around the clavulanic acid combination disc is increased $>5 \mathrm{~mm}$ vs. the $3^{\text {rd }}$ generation Cephalosporin's disc alone.

\section{Results and Discussion}

A total of 172 Proteus species were isolated from various clinical samples in which majority cases were isolated in Exudates (68.02\%) which is in accordance with other studies (Mordi et al., 2009; Newman et al., 2006) done worldwide. Proteus mirabilis was the most frequently isolated species 107 (62.20\%) followed by Protues vulgaris 56 (32.55\%), Providencia stuartii 6 (3.48\%) and Morganella morganii 3 $(1.74 \%)$ as shown in Figure 1.

Highest prevalence of Proteus infection was observed in the age group $\geq 50$ year age group (50\%) followed by $41-50$ years age group in which prevalence was $14 \%$ as (Table-1). All the isolates of Protues mirabilis (62.20\%) and Protues vulgaris (32.55\%) were found to be positive for production of virulence factors e.g. Urease and DNase. Proteus isolates from inpatient was highest from exudates accounting for $103(60 \%)$ of the total followed by urine 39 (22\%)-Table 2, as compared to out-patient (Felgo et al., 2010; Luelmi et al., 2014).
This finding indicates that Proteus may become a major cause hospital acquired infection in our set up if not detected and treated on time.

Isolates showing resistance to either three groups or more standard antibiotics is considered as "Multidrug resistant organism" (MDR). In this study, Multidrug resistance was observed in 122 (70.9\%) Proteus isolates of which maximum cases were found in Proteus mirabilis 79 (46\%) (Figure-2), with commonest phenotype being co-resistance to ampicillin, Ceftazidime and Aminoglycosides i.e. (Amikacin, Gentamicin). High Resistance to Quinolones (43.6\%) was also observed among the isolates as seen in Table-3. Pandrug resistance was observed in $6(3.4 \%)$ isolates which needs further testing by molecular methods to detect different resistance genes. Resistance to Imipenem was found in 16 isolates (9.3\%) of which maximum cases were Proteus mirabilis i.e12 (75\%).High antibiotic resistance was found among Proteus in other studies also (Reslinki et al., 2005; Rozalski et al., 2012; Sekowska et al., 2004; Shenoy et al., 2013).

In our study Out of $93(54 \%)$ screen positive Proteus isolates, ESBL production was confirmed by the phenotypic method in 22 (24\%) isolates with highest incidence in P.mirabilis 18 (82\%) followed by Proteus vulgaris $4(18 \%)$-Table 4. Maximum ESBL positive isolates were recovered from exudates 19 (86.3\%), in admitted patients. Although finding of $24 \%$ ESBL producers in our study was low in comparison to different part of the world and country (50$60 \%$ ). However it is similar to a study done by Senthamarai et al., (24.8\%) in 2015 from South India. None of the four screen positive Providencia stuartii isolates of our study showed ESBL production by confirmatory test. All the ESBL producing Proteus isolates were found to be multidrug resistant 
with maximum resistance against Ampicillin (100\%), Cefotaxime (100\%), Ceftazidime (91\%), and Quinolones (68\%). Only one ESBL producing Proteus isolate (4.5\%) was found to be resistant to Imipenem which indicates that Carbapenems are still the most effective antibiotic against these infections in our set up (El-Tahawy, 2000).
According to our study maximum infection in urine sample was caused by P.mirabilis (61\%) which is in accordance with Mobley at al (22) where it was found that $P$. mirabilis has a higher propensity for colonizing the urinary tract due to difference in its pathogenicity .

Table.1 Distribution of Proteus species in different age groups

\begin{tabular}{|l|l|l|}
\hline $\begin{array}{l}\text { AGE GROUP } \\
\text { (in years) }\end{array}$ & $\begin{array}{l}\text { Positive } \\
\text { isolates } \\
\text { (n=172) }\end{array}$ & \\
\hline $0-10$ & 17 & $9.88 \%$ \\
\hline $11-20$ & 6 & $3.48 \%$ \\
\hline $21-30$ & 18 & $10.46 \%$ \\
\hline $31-40$ & 21 & $12.20 \%$ \\
\hline $41-50$ & 24 & $13.95 \%$ \\
\hline$\geq 50$ & 86 & $50 \%$ \\
\hline TOTAL & 172 & $100 \%$ \\
\hline & & \\
\hline
\end{tabular}

Table.2 Distribution of Proteus isolates among inpatients and outpatients

\begin{tabular}{|l|l|l|l|l|l|l|l|l|}
\hline \multirow{2}{*}{ Isolates } & \multicolumn{4}{|l}{ Exudate } & \multicolumn{3}{l|}{ Urine } \\
\cline { 2 - 9 } & $I P$ & $\%$ & $O P$ & $\%$ & $I P$ & $\%$ & $O P$ & $\%$ \\
\hline P.mirabilis & 64 & $62.13 \%$ & 11 & $78.57 \%$ & 22 & $56.41 \%$ & 14 & $87.5 \%$ \\
\hline P.vulgaris & 34 & $33 \%$ & 3 & $21.42 \%$ & 13 & $33.33 \%$ & 2 & $12.5 \%$ \\
\hline $\begin{array}{l}\text { Providencia } \\
\text { stuartii }\end{array}$ & 4 & $3.88 \%$ & 0 & $0 \%$ & 2 & $5.12 \%$ & 0 & $0 \%$ \\
\hline $\begin{array}{l}\text { Morganella } \\
\text { morganii }\end{array}$ & 1 & $0.97 \%$ & 0 & $0 \%$ & 2 & $5.12 \%$ & 0 & $0 \%$ \\
\hline \begin{tabular}{l} 
TOTAL \\
\hline
\end{tabular} & 103 & $100 \%$ & 14 & $100 \%$ & 39 & $100 \%$ & 16 & $100 \%$ \\
\hline
\end{tabular}

NOTE: Proteus isolates were found to be most common among the in-patients (both from exudates and urine specimens) with 103(59.88\%) and 39(22.67\%) isolates respectively. 
Table.3 Pattern of antimicrobial resistance among Proteus isolates

\begin{tabular}{|c|c|c|c|c|}
\hline ANTIBIOTICS & $\begin{array}{c}\text { P.mirabilis } \\
(\mathrm{n}=107)\end{array}$ & $\begin{array}{c}\text { P.vulgaris } \\
(\mathrm{n}=56)\end{array}$ & $\begin{array}{c}\text { Prov. } \\
\text { Stuartii } \\
(\mathrm{n}=6)\end{array}$ & $\begin{array}{c}\text { M.morganii } \\
(\mathrm{n}=3)\end{array}$ \\
\hline$A M P$ & $87(81.30 \%)$ & $44(79 \%)$ & $5(83.33 \%)$ & $2(67 \%)$ \\
\hline$A K$ & $25(23.36 \%)$ & $7(13 \%)$ & $2(33.33 \%)$ & 0 \\
\hline$C A Z$ & $16(15 \%)$ & $9(16 \%)$ & $1(17 \%)$ & $1(33.33 \%)$ \\
\hline$C I P$ & $28(26.16 \%)$ & $13(23.21 \%)$ & $3(50 \%)$ & 0 \\
\hline$C N$ & $58(54.20 \%)$ & $28(50 \%)$ & $4(67 \%)$ & $1(33.33 \%)$ \\
\hline$C O T$ & $83(78 \%)$ & $37(66 \%)$ & $4(67 \%)$ & $2(67 \%)$ \\
\hline$C P M$ & $36(34 \%)$ & $17(30.35 \%)$ & 0 & 0 \\
\hline$C T X$ & $43(40 \%)$ & $21(38 \%)$ & $2(33.33 \%)$ & 0 \\
\hline$G E N$ & $37(35 \%)$ & $10(18 \%)$ & $2(33.33 \%)$ & $1(33.33 \%)$ \\
\hline$I P M$ & $7(7 \%)$ & $5(9 \%)$ & $1(17 \%)$ & 0 \\
\hline OF & $52(49 \%)$ & $19(34 \%)$ & $4(67 \%)$ & 0 \\
\hline
\end{tabular}

Table.4 Confirmed ESBL Proteus isolates

\begin{tabular}{|l|l|}
\hline Organisms $(\mathbf{n}=22)$ & ESBL Producing \% \\
\hline P.mirabilis & $82 \%$ \\
\hline P.vulgaris & $18 \%$ \\
\hline
\end{tabular}

Fig.1 Species distribution of Proteus

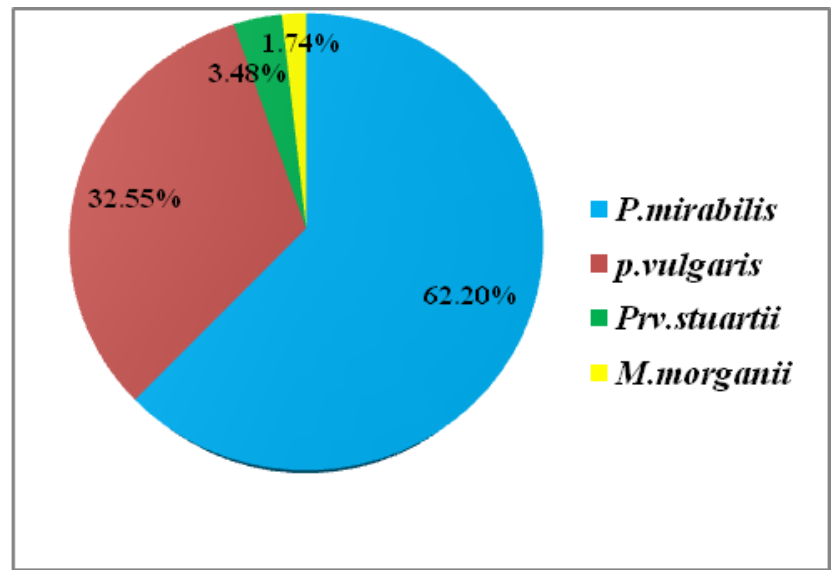


Fig.2 MDR Proteus species

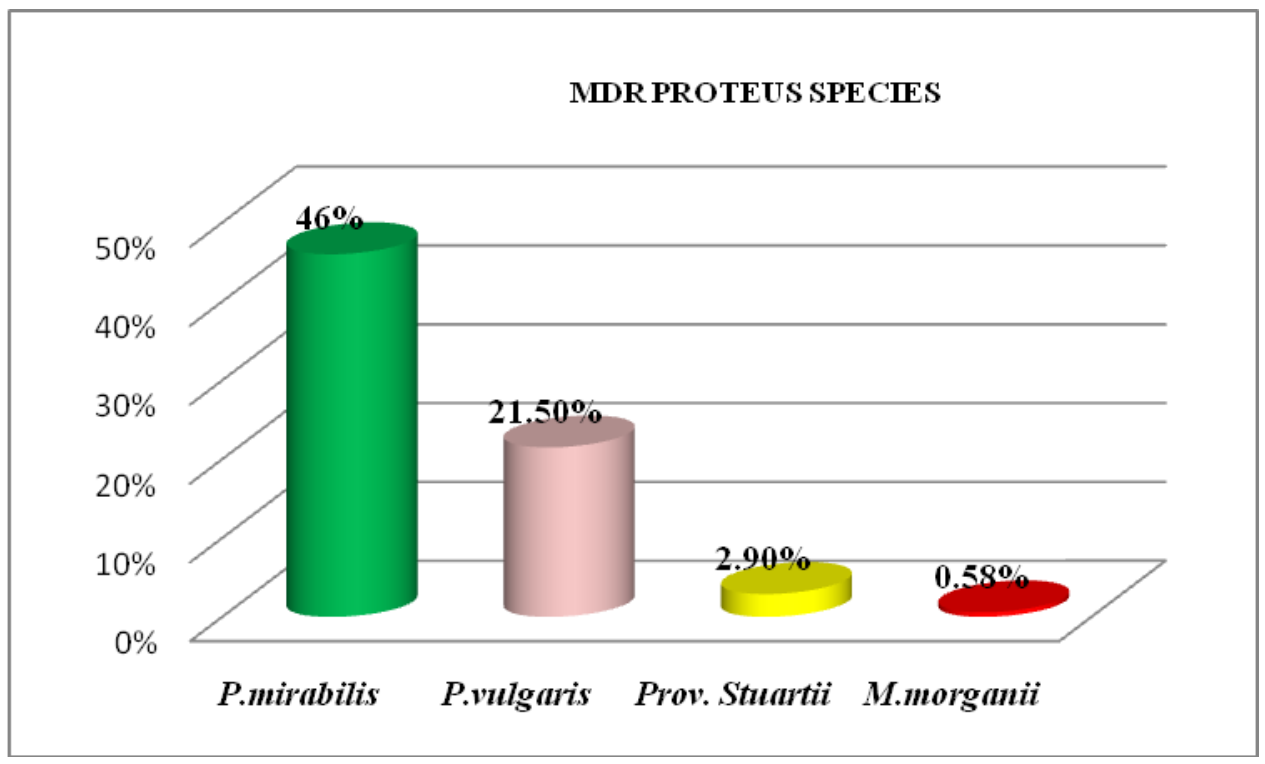

Image.1 Double disc diffusion test showing ESBL positive strain

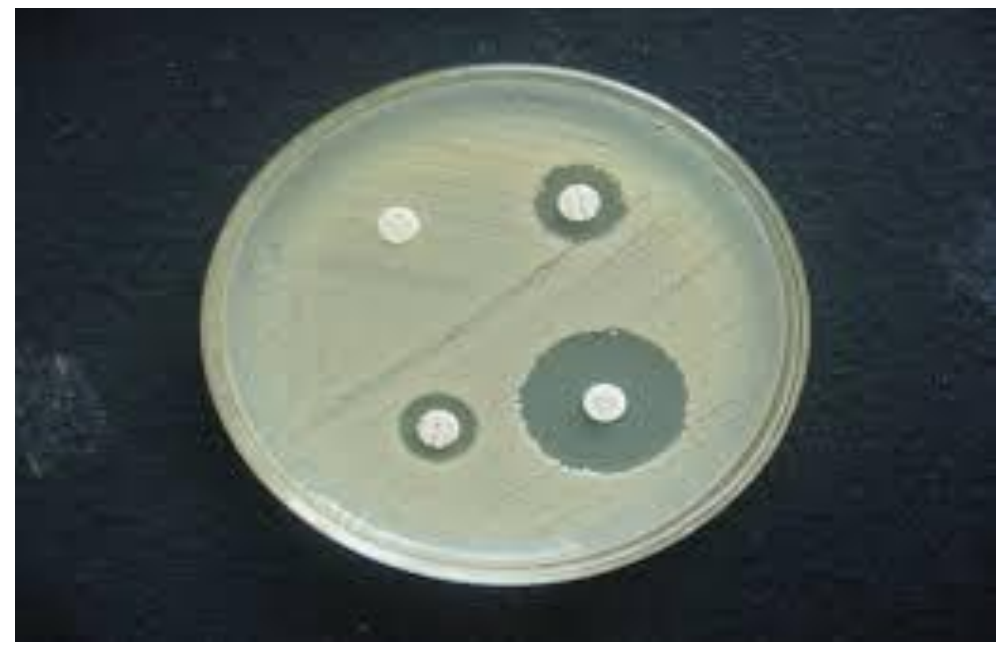

Although Escherichia coli accounts for the major cases of uncomplicated urinary tract infections Proteus ranks third as the cause of these infections particularly in hospital acquired set up (Bahaswan et al., 2013) Indiscriminate use of antibiotics particularly third generation Cephalosporins provide selective pressure among Enterobacteriaceae which is the possible cause of multidrug resistance observed among these organisms including Proteus (Levy, 1999). Since plasmids are responsible for ESBL production tend to be large ( $80 \mathrm{~Kb}$ or more) and carry resistance to several other antimicrobial agents. These organisms carrying these plasmids are also potential reservoirs of resistance genes that could be transferred to other bacterial pathogens. ESBL producing organisms cause a major problem for clinical therapeutics. The incidences of ESBL producing Proteus among clinical isolates have been steadily increasing over the past few years resulting in limited therapeutic options. Though in our 
study, ESBL producing organisms were found to be restricted to inpatients only, there is still risk of spread of these organisms to community. With the spread of ESBL producing strains in hospitals all over the world, it is necessary to know the prevalence of ESBL positive strains in a hospital so as to formulate antibiotic policy for empirical therapy in high risk units where infections due to these resistant organisms is much higher (Mathur et al., 2002).

\section{References}

Bahaswan, S.A., Shafey, H.M.E. 2013. Antimicrobial Resistance Patterns of Proteus isolates from clinical specimens. European Scientific J., 9(27): 188-202

Clinical and Laboratory Standards Institutes (CLSI). 2012. Performance standards for antimicrobial susceptibility testing; twenty-second Informational Supplement. CLSI document M100S22. Wayne, PA: Clinical and Laboratory Standard Institute.

Coker, C., Bakere, O.O and H.L.T. Mobley 2000. H-NS is a repressor of the Pr. mirabilis urease transcriptional activator gene ure R. J. Bacteriol., 128(9): 2649-2553

Collee, J.G., Miles, R.S., Watt, B. 1996. Tests for the identification of bacteria. In: Collee JG, Fraser AG, Marmion BP, Simmons A, editors. Mackie \& McCartney practical medical microbiology, $114^{\text {th }}$ ed. Edinburg, UK: Churchill Livingstone; P. 134-49.

De Champs, C., Bonnet, R., Sirot, D. Chanal, C. and J. Sirot. 2000. Clinical relevance of $\mathrm{Pr}$. mirabilis in hospital patients: A two year survey. $J$. Antimicrob. Chemother., 45: 537-539.

El-Tahawy, A.T. 2000. Bacteriology of diabetic foot infections. Saudi Med. J.,
21(4): 344-347.

Felgo, et al. 2010. "Occurrence, species distribution and antibiotic resistance of Proteus isolates: A case study at the Komfo Anokye Teaching Hospital (KATH) in Ghana. Int. J. Pharma. Sci. Res.,(IJPSR), 1(9): 347-352.

Foxman, B. 2000. Urinary Tract Infections: Incidence and risk factors. Am. J. Pub. Health, 80: 331-333.

Kamga, H.L.F., Assob, J.C.N., Nsagha, D. S., Njunda, A.L., Nde Fon P. and Tchape, G.N.E. Epidemiological studies on Proteus isolates from clinical specimens in the Laquintinie Hospital in Doula.

Levy, S.B. 1999. Antibiotic resistance: and ecological inbalancee. In Ciba Found. Symp. (Ed.), 207: 1-14

Luelmi, Z., Kandouli, C., Benlabed, K., Lezzar, A., Ilhem Mihoubi, I. 2014. Prevalence and evaluation of resistance to antibiotics of genera Proteus, Morganella and Providencia isolates in University Hospital of Constantine, Algeria. Int. J. Adv. Res., (1): 220-27.

Mathur, P., Kapil, A., Das, B., Dhawan, B. 2002. Prevalence of ESBL production gram negative bacteria in a tertiary care hospital. Indian J. Med. Res., 115: 153-157.

Mistry, R.D., Scott, H.F., Alpern, E.R., Zaoutis, T.E. 2010. Prevalence of Proteus mirabilis in skin abscesses of the axilla. J. Pediat., 56(5): 850-1.

Mobley, H.L.T. 1994. "Virulence of Proteus mirabilis in urinary tract infections. Molecular pathogenesis and clinical management" ASM Press, Washington, D.C. 245269.

Mordi, R.M., M.I. Momoh. 2009. "Incidence of Proteus species in wound infections and their sensitivity pattern in the University of Benin Teaching Hospital", African $J$. 
Biotechnol., Vol.8 (5), pp.725-730.

Nachammai, S.M., Sneka, P., Aswin Sayiram, S.J. Prevalence of multidrug resistant Proteus species from isolates of urine and pus with their antibiogram.

Newman, M.J., Frimpong, E., AsamoahAdu, A., and E. Sampane-Donkor. 2006. "Resistance to Antimicrobial Drugs in Ghana. The Ghanian-Dutch collaboration for Health Research and Development, 1-6.

Orett. 1999. Prevalence of Proteus species in urinary tract infections in a regional hospital in Trinidad. Zhonghua Yi XueZaZhi (Taipei), 62: 438-442

Pandey, J.K., Tyagi, A.K.S. 2013. Prevalence of Proteus in clinical samples, antibiotic sensitivity pattern and ESBL production. Int. J. Curr. Microbiol. App. Sci., 2(10): 253-61.

Reslinki, A., Gospodarek, E., Mikucha, A. 2005. Prevalence of multi-drug resistant Proteus species in clinical specimens and their susceptibility to antibiotics. Med. Dosw. Microbial., 57(2): $175-84$.

Rozalski, A., Torzewska, A., Moryl, M., Kwil, I., Maszewska, A., Ostrowska
Ket al. 2012. Proteus sp.-an opportunistic bacterial pathogenclassification significance and virukence factors. Folia Biologica et Oecologica, 8: 1-17.

Sawaya, Fadi, J., Sawaya, Jaber, I., Gharzuddine, Walid, Eid, Elias, V., Kanj, Souha, S. 2009. Polymicrobial gram negative pericarditis. Int. J. Infect. Dis., 13(6): 483-4.

Sekowska, A., Janicka, G., Wroblewska, J., and Kruzzynska, E. 2004. Prevalence of proteus mirabilis starins in clinical specimens and evaluation of their resistance to selected anitibiotics. Pol MerkurLekarski. 17:538-40

Shenoy, S.M., Mohit, Sinha, R. 2013. Antibiotic sensitivity pattern of clinical isolates of Proteus species with special reference to ESBL and Amp C production. Indian J. Adv. Res. 3(3): 293-4

Yah et al. 2001. Widespread Plasmid resistance genes among Proteus species in diabetic wounds of patients in Ahmadu Bello University Teaching Hospital (ABUTH) Zaria. Afri. J. Biotechnol., 6(15): n1757-1762.

\section{How to cite this article:}

Satisfaction Syntem, Himadri Dutta and M. Kalyani. 2016. Characterization of Proteus Species and Detection of Multi Drug Resistant (MDR) with Special Reference to ESBL Strains. Int.J.Curr.Microbiol.App.Sci. 5(11): 153-160. doi: http://dx.doi.org/10.20546/ijcmas.2016.511.018 